\title{
Eustachian Tube Dysfunction in Patients with Localized Amyloidosis of the Nasopharynx and Eustachian Tube
}

\author{
Anna-Christina Lauer, MD, PhD; Claudia Quast, MD; Dina Ligum, MD²; Holger Sudhoff, \\ $\mathrm{MD}, \mathrm{PhD}, \mathrm{FRCS}, \mathrm{FRCPath}{ }^{1 *}$ \\ 'Department of Otolaryngology, Head and Neck Surgery, Klinikum Bielefeld, Bielefeld, Germany \\ ${ }^{2}$ Department of Pathology, Klinikum Bielefeld, Bielefeld, Germany
}

\begin{abstract}
Introduction: A small number of cases of localized amyloidosis of the upper aerodigestive tract have been reported in the literature. Case presentation: We present two cases of dilatory Eustachian tube dysfunction caused by localized nasopharyngeal amyloidosis.

Management and outcome: Diagnostic biopsies confirmed AL amyloidosis (immunoglobulin light chain amyloidosis) of the nasopharynx and Eustachian tube. Both patients had undergone previous treatments with grommet insertions. Despite balloon dilation Eustachian tuboplasty (BET) symptoms recurred in long-term follow-up.

Discussion: Localized nasopharyngeal amyloidosis can be a rare pathology in refractory Eustachian tube dysfunction and middle ear effusion. Conclusion: Histopathology has to confirm localized amyloidosis. Due to the lack of causative medical treatment options, grommets and BET may be applied.
\end{abstract}

\section{Introduction}

Amyloidosis refers to an extremely rare group of disorders caused by extracellular deposition of abnormal fibrillary proteins ( $\beta$-fibrils). This condition can either occur locally or systemically. In systemic AL amyloidosis (immunoglobulin light chain amyloidosis), the defective bone marrow plasma cells produce monoclonal antibodies, which lead to amyloid deposits causing damage in multiple organs. Depending on the manifestation, clinical symptoms vary significantly and can lead to cardiac insufficiency and renal failure. Additionally, an involvement of lung, muscles, and soft tissues may occur [1]. Systemic AL amyloidosis is the most common subtype of amyloidosis. Another rare subtype is the localized amyloidosis, which can occur in the upper and lower airways (larynx, trachea and bronchial system), skin, and urinary tract. There are only a few reports on localized amyloidosis of the nasopharynx and none for the Eustachian tube. The derived proteins are only produced in the defected organ itself in this subtype [2,3]. A transition into a systemic disease is very unlikely. A 20 -year follow-up of 20 patients has not revealed a single case of transition [4].

Here, we report two cases of localized AL amyloidosis with nasopharyngeal deposits in the Eustachian tube, resulting in tube dysfunction that presented in our ENT department over the last two years. Previous case reports described middle ear effusion in nasopharyngeal amyloidosis, but never pathological tissue within the Eustachian tube itself.

\section{Case Reports}

\section{Patient 1}

The first patient (female, Caucasian, 46-year-old) presented with an acute hearing loss and sensation of pressure in both ears for 7 consecutive years. She had already undergone repeated T-tube insertions resulting only in a temporary clinical improvement. She complained about an intermittent bilateral tinnitus. Ear pressure was worsened with ambient pressure changes and could be equalized with Valsalva or Toynbee maneuvers. No dizziness or vertigo was reported. Due to a chronic anterior and posterior rhinorrhoea and nasal obstruction, sinus surgery was performed previously. Direct laryngoscopy with biopsies of the pharynx and the vocal cord revealed a vocal infestation of amyloidosis.

\section{Patient 2}

The second patient (female, Caucasian, 52-year-old) was first diagnosed with nasopharyngeal amyloidosis in 1989. At that time she presented with recurrent middle ear effusion of the left ear. Adenoidectomy and grommet insertion were performed. Histopathology confirmed amyloidosis. Until 2014, the patient experienced a symptom control with repeated grommet insertions. Due to chronic therapy-resistant otorrhea, the grommet was removed. Afterwards, the patient suffered from severe vertigo, left-sided tinnitus, and conductive hearing loss. In 2015, the patient was referred to our department with chronic otitis media with effusion and recurrent vertigo.

Both patients received thorough diagnostic examinations. Both patients showed a gelatinous deposit in the nasopharynx and Eustachian tube (Figure 1).

The first patient's pure tone audiogram (PTA) revealed a moderate combined right hearing loss and a low grade left sensory neural hearing loss in the left ear with a T-tube in place. The second PTA showed a left moderate conductive hearing loss, which showed chronic otitis media and a normal right hearing.

The Valsalva maneuver was negative in the affected ears of both patients. The ETDQ-7 questionnaire was rated $18 / 49$ points and 25/49 points respectively, consistent with Eustachian tube dysfunction [5]. Tubomanometry confirmed dilatory Eustachian tube dysfunction in both patients (Figure 2).

Both patients received a balloon dilation of the Eustachian tubes and biopsies of the nasopharynx and Eustachian tube orifice. Histopathology confirmed an AL-Amyloidosis in both cases (Figure 3). Further exams showed no signs of systemic disease. We referred the patients to a tertiary referral center for amyloidosis.

We performed Eustachian tube balloon dilation in both patients. However, after a 2-month interval of symptom relief, both patients showed recurrent symptoms of middle ear effusion and chronic otitis media in the follow-up. 


\section{CASE REPORT}

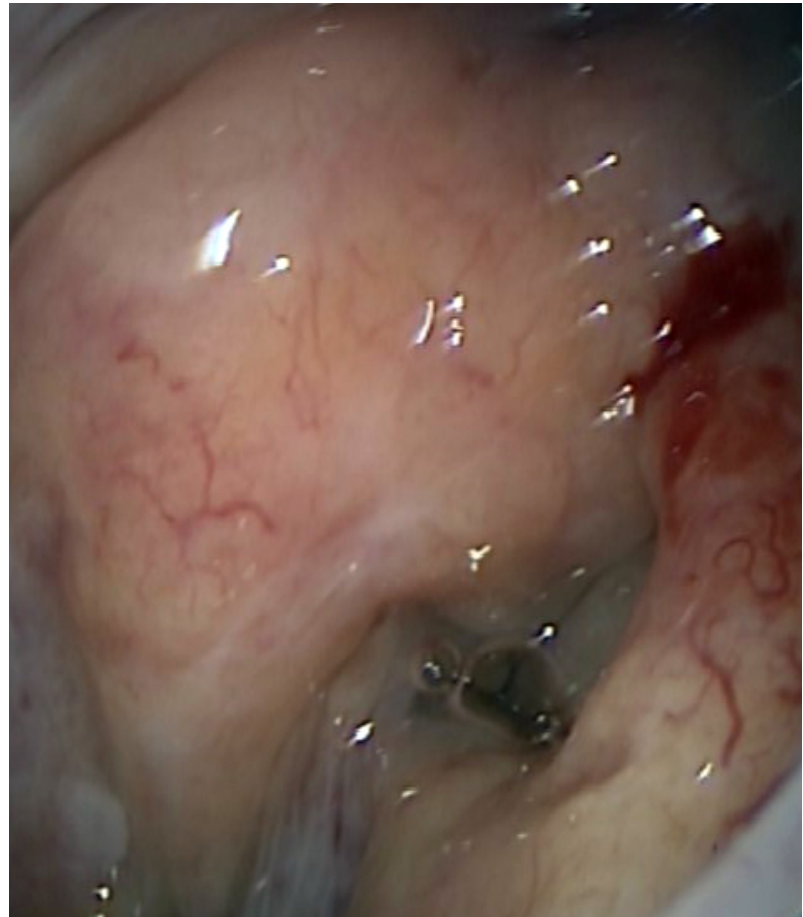

Figure 1. Patient 1 showing a gelatinous deposit in the right Eustachian tube orifice.

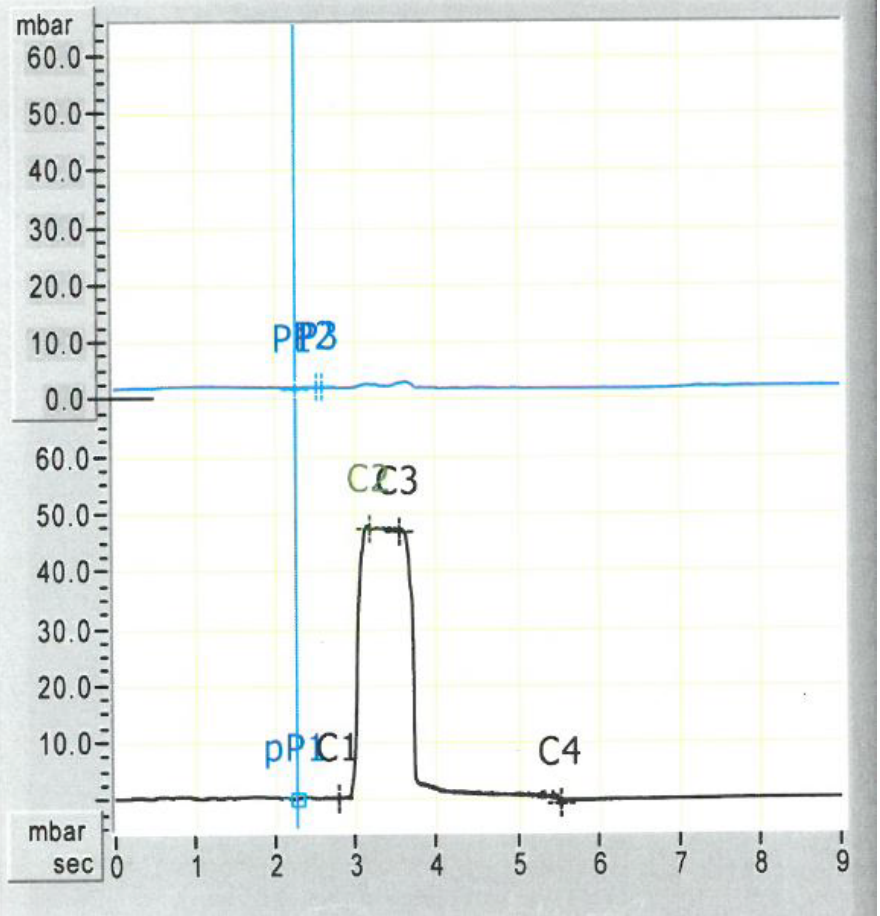

Figure 2. Tubomanometry confirmed dilatory Eustachian tube dysfunction in patient 2 (Opening-latency-index $\mathrm{R}=0$ ).

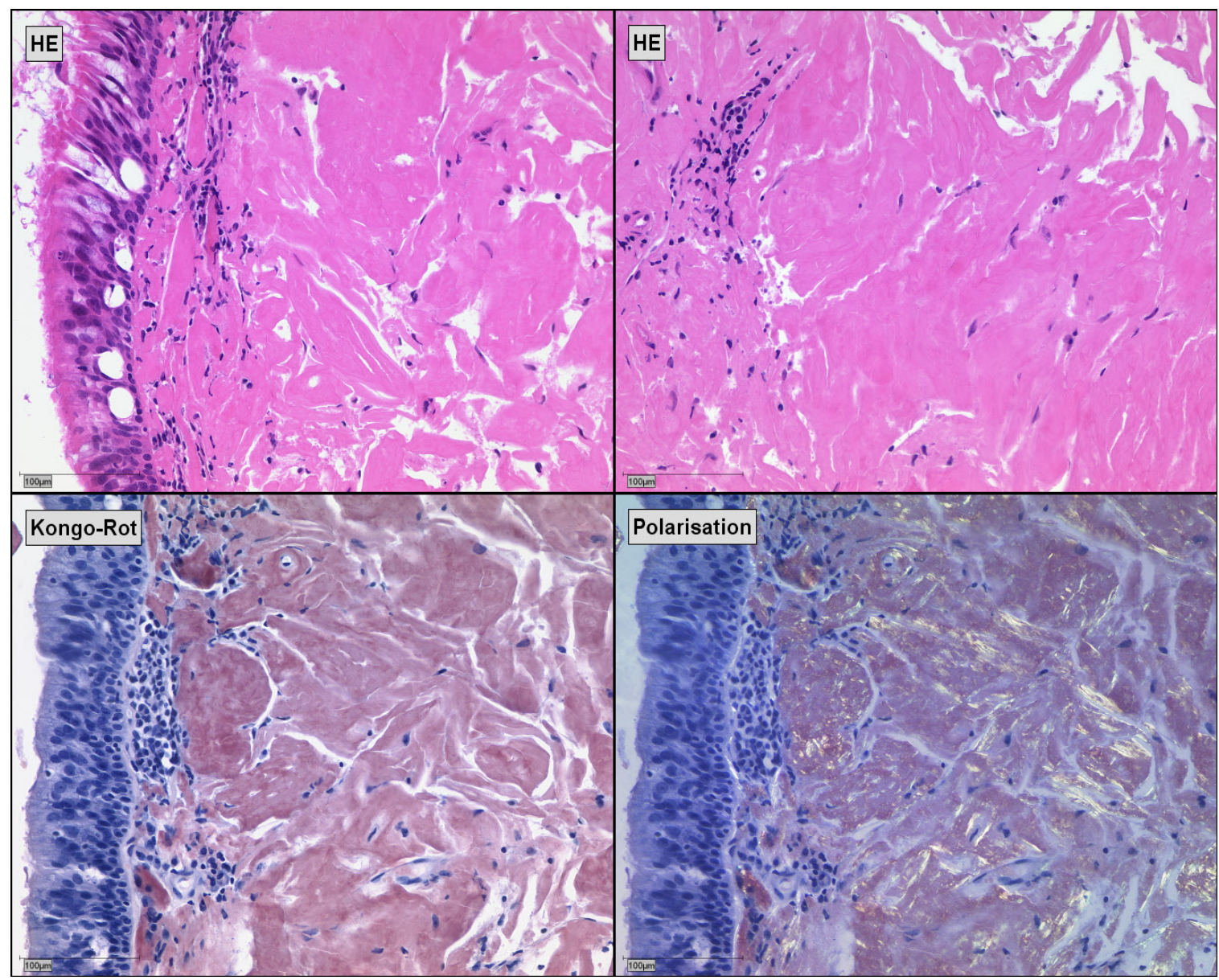

Figure 3. Histopathology of AL amyloidosis (immunoglobulin light chain amyloidosis) in patient 1 with hematoxylin and eosin staining (HE), Kongo red staining, and Kongo red staining with polarization. 


\section{Discussion}

Eustachian tube dysfunction can be differentiated into acute or chronic dilatory Eustachian tube dysfunction, baro-challenge-induced Eustachian tube dysfunction, and patulous Eustachian tube dysfunction. In dilatory tube dysfunction and baro-challenge-induced tube dysfunction, patients present similar clinical symptoms; for example, altered hearing, ear pressure and the repeated use of the Valsalva maneuver for relief. In rare cases, one-sided Eustachian tube dysfunction also manifests in vertigo, caused by a retraction of the ear drum, leading to the motion of the ossicles stimulation of the perilymph and endolymph of the cochlea, and further leading to an impairment of labyrinth function [6]. In most cases, dilatory tube dysfunction is a continuous problem [7]. The underlying factors for a dilatory tube dysfunction can be extrinsic, such as a nasopharyngeal mass obstruction of the pharyngeal Eustachian tube orifice or obstruction of the bony portion of the Eustachian tube [8]. Dilatory tube dysfunction can also be caused by intrinsic factors, e.g., an acute or chronic mucosal swelling in the nasopharynx, pharyngeal Eustachian tube orifice and mucosa due to an allergic reaction, gastroesophageal reflux disease, and chronic inflammation [9]. Those factors can also be responsible for an impaired mucosal clearance. Mucosal swelling and retention of nasopharyngeal and middle ear secretions in the Eustachian tube orifice may interfere with the physiological opening and closing of the tube impairing sufficient ventilation of the middle ear.

In localized amyloidosis, insoluble proteins are deposited in the mucosal tissue leading to mucosal swelling, nasopharyngeal masses, and possibly an impairment of the mucosal clearance. All factors can contribute to a disturbance of the pressure regulating function of the Eustachian tube and consecutive middle ear diseases. There are only a few case reports discussing the localized nasopharyngeal amyloidosis. We reviewed cases of nasopharyngeal localized amyloidosis in the literature from 1980 till today. We found 5 cases of patients with reported Eustachian tube dysfunction or middle ear effusion [6-10]. Interestingly, cases of (massive) nasopharyngeal amyloidosis without tube dysfunction have also been described [14,15]. In cases of large nasopharyngeal masses, surgical excision may lead to a symptom improvement and malignancies have to be excluded. However, in dispersed amyloid deposits in the tubal protuberance, surgical excision can lead to damages resulting in a worsening Eustachian tube dysfunction $[15,16]$. Several of the reported cases showed no further impairment after surgical removal $[10,17]$, but a massive regrowth of the lesion to a massive size has also been reported [13]. Due to the lack of medical treatment for localized amyloidosis, surgical excision and clinical follow up exams may become necessary. Life-long follow-up exams, including nasopharyngoscopy, should be recommended. Eustachian tube dysfunction in cases of localized amyloidosis may be treated by balloon Eustachian tube dilation; however, it may lead to unsatisfactory results in our cases. Further surgical approaches in literature include Quantum Molecular Resonance mediated shrinkage of the mucosa of the torus tubarius [18], laser tuboplasty [19] and a microdebrider [20]. Contributing factors, such as gastroesophageal reflux with signs of mucosal inflammation, should be addressed. In addition to reflux treatment, the usage of nasal steroids might reduce mucosal inflammation and swelling.

Both of our patients had undergone surgical and medicinal therapies to improve middle ear ventilation; therefore, a balloon dilation was an additional option. Systemic AL amyloidosis should be ruled out in all localized amyloid cases. Generally, localized disease does not progress into a systemic disease. However, mild systemic disease needs to be ruled out. Localized amyloidosis is found in both genders. The mean age at the time of diagnosis is between the $4^{\text {th }}$ and $8^{\text {th }}$ decade with a predominance of male patients $[11,21]$. There is no data on incidence and prevalence for localized amyloidosis.

Notably, several pediatric cases of localized amyloidosis of the nasopharynx have been reported. Patients presented nasal obstruction, mucoid discharge, and nose bleeding [22]. Since nasopharyngoscopy is not always applicable in children prior to surgery, the presence of amyloid can be found incidentally during adenoidectomy.

\section{Conclusions}

Localized amyloidosis should be considered as a rare pathology of Eustachian tube dysfunction. Nasal endoscopy can identify localized amyloidosis as a subtle, waxy, yellowish mass in the nasopharynx and Eustachian tube. Diagnosis should always be confirmed by histology. Other factors for an impairment of Eustachian tube dysfunction have to be excluded by thorough anamnesis and medical examination, pure tone audiogram, tympanogram, and tubomanometry. Additionally, a dynamic MRI might be useful to diagnose localized amyloidosis in the nasopharynx [23]. But, still, amyloidosis is properly diagnosed by histopathology and due to image variation, not clearly detectable in CT and MRI scans [24]. Therapeutic management includes balloon dilation and long-term grommet insertion due to the lack of conservative treatment options.

\section{Article Information}

*Correspondence: Holger Sudhoff, MD, PhD, FRCS, FRCPath Department of Otolaryngology, Head and Neck Surgery, Klinikum Bielefeld, Teutoburger Str. 50, 33604 Bielefeld, Germany. Email: holger.sudhoff@rub.de

Received: Nov. 2, 2017; Accepted: Nov. 27, 2017; Published: Jan. 16, 2018

DOI: $10.24983 /$ scitemed.aohns.2018.00050

Copyright $\odot 2018$ The Author(s). This is an open-access article distributed under the terms of the Creative Commons Attribution 4.0 International License (CC-BY).

\section{Funding: None}

Conflict of Interest Disclosures: The authors declared no potential conflicts of interest with respect to the research, authorship, and/or publication of this article.

\section{Keywords}

Eustachian tube; localized Amyloidosis; nasopharynx.

\section{References}

1. Merlini G, Seldin DC, Gertz MA. Amyloidosis: pathogenesis and new therapeutic options. Journal of Clinical Oncology 2011;29(14):19241933.

2. Simpson GT 2nd, Strong MS, Skinner M, Cohen AS. Localized amyloidosis of the head and neck and upper aerodigestive and lower respiratory tracts. Annals of Otology, Rhinology, and Laryngology 1984;93(4):374-379.

3. Schönland SO, Bochter T, Kristen AV, Ho AD, Hegenbart U. Aktuelle Diagnostik und Therapie der Leichtkettenamyloidose. Pathologe 2009;30(10):205-211.

4. Biewend ML, Menke DM, Calamia KT. The spectrum of localized amyloidosis: a case series of 20 patients and review of the literature. Amyloid 2006;13(3):135-142.

5. McCoul ED, Anand VK, Christos PJ. Validating the clinical assessment of eustachian tube dysfunction: the eustachian tube dysfunction questionnaire (ETDQ-7). Laryngoscope 2012;122(5):1137-1141.

6. Kim H-Y. Vertigo due to Eustachian Tube Dysfunction. Archives of Otorhinolaryngology - Head \& Neck Surgery 2017;1(1):4-5.

7. Schilder AG, Bhutta MF, Butler CC, et al. Eustachian tube dysfunction: consensus statement on definition, types, clinical presentation and diagnosis. Clinical Otolaryngology 2015;40(5):407-411.

8. Paltura C, Can TS, Yilmaz BK, Dinç ME, Develioğlu ÖN, Külekçi M. Eustachian tube diameter: is it associated with chronic otitis media development? American Journal of Otolaryngology 2017;38(4):414-416.

9. Al-Saab F, Manoukian JJ, Al-Sabah B, et al. Linking laryngopharyngeal reflux to otitis media with effusion: pepsinogen study of adenoid 
tissue and middle ear fluid. Journal of Otolaryngology - Head \& Neck Surgery 2008;37(4):565-571.

10. McCluney N, Shakeel M, Dallas A, Hussain A, Chapman A. Amyloidosis of the nasopharynx: an unexpected cause of unilateral middle ear effusion. Journal of the College of Physicians and Surgeons Pakistan 2011;21(11):706-707.

11. Patel A, Pambuccian S, Maisel R. Nasopharyngeal amyloidosis. American Journal of Otolaryngology 2002;23(5):308-311.

12. Durbec M, Ambrun A, Barnoud R, Poupart M, Pignat JC, Merrot O. Localized nasopharyngeal amyloidosis. European Annals of Otorhinolaryngology, Head and Neck Diseases 2012;129(3):160-162.

13. Mirza AH, El-Shunnar S, Sama A. Nasopharyngeal amyloidosis: an unusual cause of unilateral hearing loss. Journal of Surgical Case Reports 2013;2013(2):rjs048.

14. Tsai YT, Huang CM, Chen YJ, Leu YS. Localized nasopharyngeal amyloidosis - a case report. Tzu Chi Medical Journal 2005;17:353-355.

15. Chen Y-S, Li W-Y, Ho C-Y. Localized nasopharyngeal amyloidosis. Journal of the Chinese Medical Association 2010;73(10):549-552.

16. Lesserson JA, Finn DG. Endoscopic treatment of amyloidosis of the nasopharynx. American Journal of Rhinology \& Allergy 1995;9(1):43-47.

17. Salturk Z, Akdağ K, Atar $Y$, et al. Primary localized amyloidosis in na- sopharynx: a rare case. Annals of Otology, Rhinology \& Laryngology 2016;3:13-14.

18. Di Rienzo Businco L, Di Mario A, Tombolini M, Mattei A, Lauriello M. Eustachian tuboplasty and shrinkage of ostial mucosa with new devices: including a proposal of a classification system. HNO. 2017;65(10):840-847.

19. Poe DS, Grimmer JF, Metson R. Laser eustachian tuboplasty: twoyear results. Laryngoscope 2007;117(2):231-237.

20. Metson R, Pletcher SD, Poe DS. Microdebrider eustachian tuboplasty: a preliminary report. Otolaryngology-Head and Neck Surgery 2007;136(3):422-427.

21. Kyle RA, Linos A, Beard CM, et al. Incidence and Natural History. Blood. 1992;79(7):1817-1822.

22. Domínguez S, Wienberg $\mathrm{P}$, Clarós $\mathrm{P}$, Clarós A, Vila J. Primary localized nasopharyngeal amyloidosis. a case report. International Journal of Pediatric Otorhinolaryngology 1996;36(1):61-67.

23. Asaumi J, Yanagi $Y$, Hisatomi M, Konouchi H, Kishi K. CT and MR imaging of localized amyloidosis. European Journal of Radiology 2001;39(2):83-7.

24. Georgiades CS, Neyman EG, Barish M a, Fishman EK. Amyloidosis: review and CT manifestations. Radiographics 2004;24(2):405-416. 